\title{
The elephant in the room
}

\author{
Advertising science as a driver of economic growth is a long-term losing strategy
}

\author{
Georgi K Marinov
}

W ith few exceptions, the amount of money that countries invest into research has stagnated or declined in real value measured against inflation or has even been slashed in absolute terms. The result is that success rates for grant applications have decreased to $10 \%$ or below in some countries, which means that scientists need to submit an average of ten proposals to have one funded. This forces many of them to spend a lot of their time and energy writing grants instead of thinking about or doing research. Worse, there is a growing feeling that the increasing competition for funding and positions is eroding the integrity of science and is leading to increased research misconduct by desperate researchers [1]. Basic research has been particularly hard hit as there has been a general push to direct research funds toward "useful" studies with more practical applications.

"The constant use of economic arguments in defense of research funding perpetuates a rarely articulated but implicit misconception that the natural sciences should be subservient to economics in the pecking order of intellectual authority"

The reasons for this trend have been extensively discussed and go beyond the problem of flat research budgets. Academic research operates as a Ponzi scheme with established scientists running large research groups that are mostly staffed by graduate students and postdoctoral researchers, most of whom are working with the goal of eventually setting up their own laboratories.
As the "birth rate" of these trainees significantly exceeds the rate at which older researchers retire, the system can only work if the conditions allow constant expansion, which has been the case for most of the second half of the $20^{\text {th }}$ century, but is no longer true in most countries [2]. In addition, the physical scientific infrastructure has equally been expanding and requires ever more funding for maintenance and operation.

This is where science advocacy has a role to play to convince politicians to allocate more money for research. The main argument is usually to highlight the role of research as a driver of economic growth and competitiveness: "The budget deficit is serious. But escaping from its clutches requires economic growth as well as budget reductions. Well over half of U.S. economic growth in the past century can be traced to investments in science and technology. To compete in the global economy, the United States must remain a leader in science and technology. For that to happen, the Senate must restore funding for science in the fiscal year 2011 budget. Failure to do so would relegate the United States to second-class status in the scientific community and threaten economic growth and prosperity for future generations of Americans" [3]. Basic research is defended on similar grounds as it provides the knowledge and human resources for more applied work. However, there are some serious problems with this approach to convincing society that it should pay for more research.

7 he first problem is the nature of science itself. What is and what is not science is notoriously difficult to define precisely, but it is quite certain that there is widespread confusion between science and technology, with the two being equivalent in the minds of many. However, science is best understood as a collection of methodological tools for understanding the world. Technology is a secondary effect based on the accrued knowledge from science, and it should not on its own be the main goal of research. Advertising science as a booster of economic growth via new technologies only feeds into this misconception.

"It is further into the future
when things will become really
grim if we continue with
business as usual."

This leads to the second problem: the devaluation of knowledge as an abstract good. If science is funded solely for economic gains, then what good is research and knowledge that has no practical benefits? As mentioned above, a worrying trend over recent years has been the major shift of emphasis toward funding research with direct practical applications. Even when fundamental research is explicitly defended, it is still done on the basis of potential longterm economic benefits, which devalues its intrinsic importance.

The third problem is the increasing subservience of the natural sciences to economics. The constant use of economic arguments in defense of research funding perpetuates a rarely articulated but implicit misconception that the natural sciences should be subservient to economics in the pecking order of intellectual authority. This view persists despite the fact that the global economy is only a tiny part of the natural world and is therefore constrained by physical and biological processes, an understanding of which is provided by the natural sciences. 


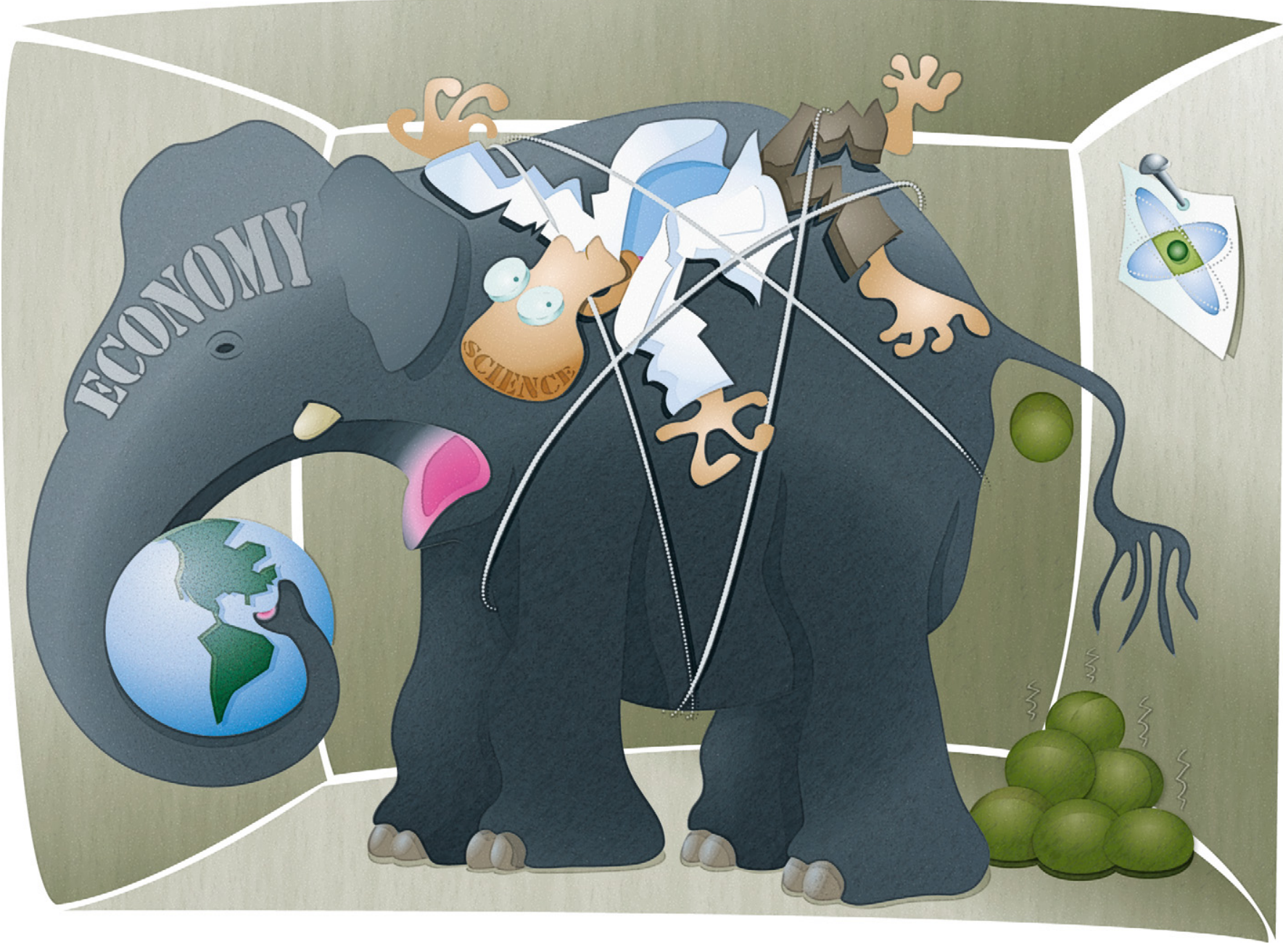

Lastly, it is the acceptance of perpetual economic growth as the ultimate good that poses a major hurdle. The idea of infinite economic growth clashes head on with our most basic scientific understanding of the physical world. On a general level, everything that happens in the economy uses energy and material resources, but the Earth is a finite sphere, with a finite endowment of recoverable natural resources, finite capacity to absorb our waste, and a limited energy supply from the sun. Even if we somehow managed to discover an unlimited and perfectly clean source of energy, if energy consumption keeps growing the planet would still suffer catastrophic climate change owing to the release of waste heat [4]. It is often argued, of course, that economic growth can be decoupled from energy and resource consumption through improved efficiency, but this has neither happened in practice nor do such propositions account for physical constraints on efficiency improvements.

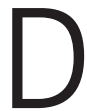
ata from a wide range of scientific disciplines show that human civilization has already entered a state of ecological overshoot relative to the carrying capacity of the planet $[5,6]$. Climate change is obviously the most visible result, but other effects include the depletion of nonrenewable resources-fossil fuels, phosphate fertilizers, minerals and ores-the use of renewable resources at unsustainable rates - such as freshwater aquifers and topsoil-the dramatic loss of biodiversity, the destruction of ecosystems, and more.

Each of these crises is directly linked to the expanding footprint of human civilization. The question then is whether it is prudent to call for more funding by promising more economic growth in return when continued expansion of the economy is in direct contradiction with scientific evidence that this is not sustainable. Scientists have been fighting battles with creationism, climate change skepticism, the anti-vaccination movement and many others, but the idea that economic growth can and will continue indefinitely is not only given a pass, but is often actively embraced. The obvious argument in defense of current practices is that scientists have no other choice, even if they understand the consequences, otherwise they will not get funded. This may be factually true for the short-term, but it ignores the long-term consequences, which are much worse than any short-term negative impacts on research funding.

There is also the matter of what the mission and core values of science are: namely to uncover how the world works in an objective way. This is a proud tradition built over centuries; modern science is the intellectual heir to millennia of human efforts to understand the natural world. It is a good idea to take an equally long-term view of the future. Doing so eliminates most justification for advertising science as a driver of economic expansion. 
G iven the impossibility of infinite growth, it is worth asking what consequences tying science's success to economic growth will have when growth inevitably ends. Facing sustained economic stagnation or contraction, societies will be less willing to invest their dwindling resources into basic research. Eventually, all of research might be hit, when it becomes apparent that investments no longer provide economic benefits. Worse still, the credibility of science might suffer. Scientists have long been portrayed by the media and by themselves as high priests of a technological society who can come up with innovations and technological solutions to address all problems. As it becomes increasingly impossible to live up to such promises, the public might lose faith in science as an institution. The continued promotion of the idea that the main function of science is to serve the economy makes such a future scenario all the more probable. We might already be witnessing the early stages of this process: one interpretation of the continuing global economic stagnation with its negative effects on research is the decline in net energy availability throughout the economy after the peak in conventional oil production in the mid-2000s [7].

\section{"The idea of infinite economic growth clashes head on with our most basic scientific understanding of the physical world"}

It is further into the future when things will become really grim if we continue with business as usual. Eventually, civilization is expected to collapse under the combined stress of declining resources and steadily worsening climatic and environmental conditions. History provides many examples of civilizations that declined due to economic or environmental causes, and we know what usually happens to scientific and cultural legacies in such cases. The fall of the Roman Empire, for instance, even though it was only partial, destroyed much of the cultural, scientific and technological knowledge of the ancient world. The knowledge that survived was preserved by the Byzantine Empire and the Arabic world and only later "rediscovered" by European scholars.
Today's scientific knowledge is orders of magnitude larger and more complex and diverse than what was lost after the fall of Rome. Moreover, it relies on a fragile infrastructure for its preservation, ranging from electronic databases to specimen collections to immaterial technical expertise. Advanced scientific knowledge is therefore highly vulnerable to societal upheaval and unlikely to be preserved in a civilizational collapse - even if that process is gradual - as support for scientific institutions evaporates, the infrastructure crumbles, education declines and experts are no longer able to train students to preserve and expand on their work.

Even worse, most of that knowledge might never be rediscovered. Industrial civilization is not simply the product of scientific and technological advances; both depend on each other. Particle physics theories are not sufficient on their own without complex machines such as the Large Hadron Collider to test them, and sophisticated bioinformatics algorithms are of little use without the infrastructure for generating, storing and processing genomic data. Only an advanced industrial society is able to organize the material and human resources to support research of this magnitude. It is not clear whether such a level of complexity and organization would be achievable in the future, as it is dependent on energy and natural resource inputs that might become irreversibly exhausted in the future. Thus, much of our scientific knowledge might be lost forever to the detriment of future societies.

sn't it therefore worth asking how much it matters whether a few more years or decades of funding for research can be secured by promising economic growth if the long-term consequences are the potentially irreversible destruction of scientific knowledge and expertise? Would it not be better for scientists to use their intellectual credibility to challenge conventional economic wisdom and to catalyze a transition toward a steady-state economy, hopefully preventing the worst consequences of business-as-usual behavior? This is a complex challenge with an uncertain outcome, and the window of opportunity for action is rapidly closing; yet, it is clearly the correct course of action for scientists to adopt if disaster is to be avoided.

The obvious first step is to raise awareness and achieve unity among scientists themselves. As a community, we should abandon the practice of advertising the economic benefits of scientific research and clearly communicate to the rest of society the physical limits to growth. The importance of unity is highlighted by the case of climate science where a small number of dissenters have been sufficient to create the impression of a much larger controversy than warranted by the evidence, but achieving it is not straightforward. Individual scientists in various fields have been warning about ecological overshoot for decades, but the scientific community has only united around particular issues such as reductions in greenhouse gas emissions, while ignoring the elephant in the room: perpetual growth.

\section{“Today's scientific knowledge is orders of magnitude larger and more complex and diverse than what was lost after the fall of Rome"}

Several factors make achieving unity difficult. First, there is a mismatch between the short-term interests of individual scientists and research institutions and the longterm interest of science and society. In the absence of collective action on the issue, individual scientists have to advertise the economic benefits of their research if they want to get funded, while many research fields and projects are already mostly focused on the pursuit of such applications.

Second, the exponential expansion of the academic research system has traditionally been supported by and linked to the expansion of the economy. On its own, and through the resulting ever closer integration of universities with business and industry, this dependency may stifle the open expression of ideas that run counter to embracing economic growth.

Third, techno-optimism, and its more extreme cousin techno-utopianism, is widespread, together with the belief that technology and human ingenuity can resolve all resource limitations and ecological problems. Being optimistic about one's research project is indispensable for scientific progress, but it is not a wise strategy for a society to rely on yet-to-be-developed or yet-to-be-conceived technologies, especially given that some of the major achievements of science have 
been in identifying what is not possible: the laws of thermodynamics being a particularly relevant example.

\section{"... the scientific community has only united around particular issues such as reductions in greenhouse gas emissions, while ignoring the elephant in the room: perpetual growth"}

Finally, the continuous fragmentation of science into subfields combined with the growing demands on researchers' finite time leave many with little opportunity to inform themselves about issues outside of their fields such as the state of the environment, depletion of nonrenewable resources, or the Ponzi-scheme nature of the economy, let alone integrate all that information into a coherent understanding. As a result, environmental problems are often considered in isolation, and solutions are proposed that do not work in the complex interrelated real world.

$\mathrm{E}$ ven if all these trends are reversed to achieve consensus, it may not be sufficient. Because modern academic institutions can currently only function in a state of constant expansion, transitioning to a steady state within academia is vital, both because of the impending end of economic growth and because of the moral need to lead by example when presenting strong challenges to commonly held beliefs.

It is not clear whether even a concerted effort to convince politicians and society to embark on a transition toward a steady-state economy will have any effect. The experience with climate change once again is instructive: despite general scientific consensus and wide publicity about the problem, no real measures have been taken to substantially reduce emissions. A lot has been written about the economic interests behind climate change skepticism, and how the organizational structure of corporations and governments has prevented efficient emission reductions. These factors undoubtedly play a major role, but they do not tell the whole story. It seems that behind this inaction is a clash of worldviews, which underlies the disregard of scientific facts by the individuals in power. It is easy for scientists to forget that the vast majority of the population does not see the world as driven by the inviolable laws of physics. Most political and industry leaders have backgrounds in businessrelated field or the humanities with little training in the natural sciences; as a result, their worldviews center around the relationships between humans, while once in positions of power, they have even less time to fully understand recent scientific developments and their implications. For example, knowledge of the geological history of the planet and the major cataclysms in it is vital for understanding the dangers of climate change, but how many times have we seen a politician make reference to these events in their speeches?

Nowhere is this disconnect more acute than in the field of economics. Mainstream economists - even the more environmentally aware among them [8] - have refused to accept the existence of limits to economic growth, invoking instead the supposedly infinite powers of the free market and human ingenuity to overcome environmental limitations. Alternative approaches such as ecological economics [9] have been almost completely marginalized.

B ridging the gulf between science and the humanities is not a new problem; C.P. Snow's famous Two Cultures article was first published in 1959. Unfortunately, little has changed since, yet such change is vital if a more sustainable future is to be achieved. There is a lot that scientists can do to improve the situation through public outreach efforts, interdisciplinary conversations, and via changes in educational curricula in their academic institutions. It is not very likely that the current generation of politicians, business leaders and economists will change the way they perceive the world, thus hope lies in future generations. Increasing the scientific content of the curriculum across the board, with emphasis on principles and methodology rather than narrow technical knowledge, is a step forward, while in the case of economics, the intellectual argument over the issue of infinite growth has to be finally won. Otherwise, the institution of the university might be judged by future historians, if there are any, to have miserably failed in its most important task. Improving the level of understanding between science and society, and abandoning narrowly defined GDP- measured economic growth as the ultimate good, could also improve support for basic research, as it would lead to a wider appreciation for the goals and nature of science and the intrinsic importance of fundamental knowledge.

Preventing the politicization of the issue is another thorny problem, once again well illustrated by climate science. In many countries, the acceptance of the scientific consensus is divided sharply across party lines and driven by political allegiances rather than objective considerations. In principle, there should be no reason why pointing out that the economy cannot grow forever should be politicized as there are no political parties of significance holding that view. However, given that growth is a core feature of the current socioeconomic system, there is no escaping the fact that the system will have to change. This inevitably opens room for political attacks and accusations of hidden agendas. Preventive measures such as pointing out that the sustainability crisis is physical in nature and independent of politics before politics is even brought up might be a solution, and social scientists and psychologists could provide useful insight into the optimal strategies for communicating the subject.

\section{"Industrial civilization is not simply the product of scientific and technological advances; both depend on each other"}

This is by no means a complete discussion of the problem, but it highlights the context within which the current scientific funding crisis developed and will further unfold. Reductionist strategies aimed at obtaining short-term gains can be harmful in the long-term and for the system as a whole, even when these achieve immediate objectives. Instead of actively communicating to the public, the best scientific understanding of the causal relationship between economic growth, environmental degradation and resource depletion, and the threats these pose to industrial civilization, the scientific community has voluntarily placed itself in a subservient position to economics and has implicitly and often explicitly supported perpetual economic expansion. By doing so, it is endangering not only its own survival, but also that of all of humanity. 


\section{Conflict of interest}

The author declares that he has no conflict of interest.

\section{References}

1. Casadevall A, Fang FC (2012) Reforming science: methodological and cultural reforms. Infect Immun 80: 891 - 896

2. Alberts $B$, Kirschner MW, Tilghman S, Varmus H (2014) Rescuing US biomedical research from its systemic flaws. Proc Natl Acad Sci USA 111: $5773-5777$
3. Orbach RL (2011) Research vital to economic growth. Science 331: 1113

4. Chaisson EJ (2011) Long-term global heating from energy usage. EOS Trans Am Geophys Union 89: $253-254$

5. Wackernagel M, Schulz NB, Deumling D, Linares AC, Jenkins M, Kapos V, Monfreda C, Loh J, Myers N, Norgaard R et al (2002) Tracking the ecological overshoot of the human economy. Proc Natl Acad Sci USA 99: 9266 - 9271

6. Rockström J, Steffen W, Noone K, Persson A, Chapin FS III, Lambin EF, Lenton TM, Scheffer
M, Folke C, Schellnhuber HJ et al (2009) A safe operating space for humanity. Nature 461: $472-475$

7. Murphy DJ, Hall CA (2011) Energy return on investment, peak oil, and the end of economic growth. Ann N Y Acad Sci 1219: 52-72

8. Krugman $P$ (2014) Slow steaming and the supposed limits to growth. The New York Times October 7.

9. Daly H, Farley J (2004) Ecological Economics: principles and Applications. Washington: Island Press 